\title{
Antropología del Género. Identidad sexual y géneros alternativos: un estudio sobre la homosexualidad femenina.
}

$M^{a}$ Concepción Unanue Cuesta

Director: Dr. Óscar Fernández Álvarez

Tesis doctoral defendida el 21 de enero de 2016

El lesbianismo es una realidad muy desconocida a nivel social y siguiendo la línea de autores/as como Fuss (1999), Francisco, Andrea y Moliner (2011), Trujillo (2009), Suárez Briones (2013), Sanfeliú (1996) o Platero (2009), nos atreveríamos a decir que incluso a nivel de investigaciones, y no porque en los últimos tiempos no exista un creciente interés por investigar y acercarse a esta realidad, desde muy diversas disciplinas. Más bien diríamos que una de las dificultades que tiene realizar una investigación que aborde lo lesbiano, es la invisibilidad de las lesbianas y el difícil acceso ellas, fuera de los grupos de activismo.

Y con respecto a la investigación, como la mayoría de los trabajos desde diferentes perspectivas sobre el tema en los últimos 10 años, siguiendo a Sala (2008), Osborne (2012) y Mira (2004), podríamos decir que son desarrollados por parte de las propias lesbianas, y la mayor parte de estas investigaciones tienen una motivación común de sus autoras, empoderar al colectivo devolviéndole la voz que siempre ha debido tener para recuperar su historia, estructurar su biografía, y hacerse visibles desde su persona, que sean las propias voces lesbianas las que hablen, evitando que su historia y su realidad, sean "secuestradas" e interpretadas por quienes de manera más o menos activa y de manera más o menos consciente colaboran a su invisibilización y a “ocupar" sus propias realidades lésbicas.

Por otra parte, la diferencia de los contextos en los que estas personas viven, provoca una gran interacción en las redes sociales, chats, foros temáticos, como realidad alternativa a la que acceder para obtener información, socializarse, plantear dudas, conocer gente con la que poder salir y hablar, en definitiva socializarse en un contexto seguro para ellas.

Según proponen entre otros/as Aparici (1996), Arriazu (2007) o Hine (2004) si en todo trabajo de campo es necesario que el/la investigador/a sea capaz de adaptarse a la realidad de su grupo objeto de estudio, en este caso es necesario además que sea capaz de conocer y manejar las nuevas tecnologías que estas personas utilizan en su vida diaria para establecer vínculos y relacionarse. Por ello cobran una gran importancia las nuevas tecnologías como "contexto social" y como "contexto geográfico virtual". 
Además de conocer y manejar los contextos cibernéticos, en los que las lesbianas se relacionan, interactúan, preguntan dudas, hacen amistades y usan para tener algún referente o grupo de ellos que les haga más fácil el propio desarrollo personal, tendremos que aplicar herramientas profesionales compatibles con la recopilación de datos e información en internet, ser capaces de aplicar la denominada "etnografía virtual”, que nos permita investigar y llegar a un análisis de las realidades.

La invisibilización de la realidad lésbica es un círculo viciado que se retroalimenta, debido a ella, apenas hay referentes reales, por lo que los estereotipos son creados de forma artificial, en base a un imaginario que carece de base cierta, o incluso creados con muy diversas intenciones (industria del porno, control social, señas de identificación lésbica...). Pero a su vez estos estereotipos producen una opinión social que nada tiene que ver con el colectivo de lesbianas, lo que refuerza la estigmatización social y a su vez el deseo de estas personas para no ser identificadas como tales. Pero sin lesbianas que den el paso y se muestren con libertad, no podemos tener referentes reales, que retiren los estereotipos creados Esteban (2004), Gauntlett (2002), Platero (2009).

Los medios de comunicación con las construcciones de imágenes y las representaciones que hacen de las lesbianas a través de los personajes en series, webseries y películas, no son desde luego el mejor lugar en el que buscar y aprender, más bien, me atrevería a decir que todo lo contrario. La televisión como medio de comunicación más consumido, tiene gran influencia en los procesos de socialización y por tanto sería un entorno ideal para rastrear el discurso social y el imaginario colectivo, cuestión que abordaremos en esta investigación con el análisis de las series y películas más referidas por las participantes, como sostienen entre otros/as Chatman (1990), Berger y Luckmann (1978), Fiske (1997), Platero (2008), González (2011).

Forés \& Grané (2008), Turkle (1997), Giddens (1992), Dancecy (1990), entre otros/as sostienen que la falta de referentes reales no solo perjudica a la sociedad en su conjunto, puesto que ignoran una parte de la diversidad, perjudica y mucho a otras lesbianas que están en la etapa de asunción de su propia identidad, que se encuentran fuera de lugar, que se sienten mal o que incluso piensan que tienen una enfermedad mental, como he podido comprobar a raíz de los testimonios de algunas de las personas que han accedido a participar en la parte empírica de este trabajo.

Esta falta de visibilidad, se refleja en una falta de representación en los grupos LGTB+, donde siguiendo la tónica social, los espacios, los turnos y recursos están en manos de los gais, quienes a pesar de ser gais, son hombres y conservan las ventajas 
provenientes de las masculinidades hegemónicas Giddens (1992).

La forma en la que se desarrolla la investigación tiene la intencionalidad de poner en el centro a las lesbianas como auténticas y únicas protagonistas, de tener en cuenta sus aportaciones y su información en todo momento, para que los resultados sean lo más representativos posible de sus inquietudes y demandas, y no solamente una interpretación, o un análisis desde fuera, cuestión de la que se quejaron desde el primer momento las personas que aceptaron participar en la investigación, y por la que rehúsan participar en estudios.

Estas mujeres -incluso desde antes de definirse como lesbianas-, han sufrido una doble o múltiple discriminación, una por su condición de mujer, otra por su orientación sexual, y varias que pueden añadirse por diversas condiciones (etnia, clase social, diversidad funcional, lugar de residencia...) (De Lauretis, 1993). Este hecho se ha materializado, junto con muchos otros, en una invisibilidad que se extiende a casi todos los ámbitos de la sociedad. Sin embargo, desde hace unas décadas, el movimiento activista lésbico ha luchado por visibilizarse en nuestra sociedad, dentro y fuera de los movimientos gais. Este tipo de activismo ha pasado por diferentes etapas y reivindicaciones hasta llegar al momento actual, caracterizado, en general, por una gran agitación social y política que se extiende, sin duda, a toda nuestra sociedad.

Encontramos mucha bibliografía sobre homosexualidad, (la mayoría referente exclusiva, o casi exclusivamente, a la homosexualidad masculina), también encontramos mucha bibliografía sobre cuestiones de género y teorías queer (durante los últimos años con una mayor presencia, aunque todavía limitada, de autoras españolas). Específicamente en cuanto a identidades lésbicas, encontramos una relativamente amplia bibliografía, aunque, por supuesto, mucho menor que aquella que tiene por objeto a los hombres homosexuales; sin embargo, cuando unimos lesbianismo y antropología, activismo o cambio social, medios de comunicación o con ciberespacio, la literatura al respecto se ve bastante reducida, siendo, en la mayoría de los casos, una bibliografía editada por asociaciones u organizaciones LGTB+.

El trabajo consta de dos partes más amplias que son el Marco Teórico y la Investigación Empírica, dentro del Marco Teórico hay varios capítulos que responden a una revisión bibliográfica y documental, desde la que se intenta dar una base teórica a la parte empírica. La Investigación Empírica refleja el trabajo de campo propiamente dicho.

Dentro del Marco Teórico tenemos: una revisión del estado de la cuestión, 
conceptos básicos que ayudan a situarnos para abordar el posterior análisis bibliográfico, también contienen un breve repaso del género y los estudios comparativos de etnografías a través de la antropología.

Se analiza brevemente la relación entre cultura y relaciones sexuales entre mujeres, desde la antropología.

Para pasar finalmente a un breve repaso por el lesbianismo desde el punto de vista histórico y geográfico.

Se revisan:

El desarrollo de la identidad de la persona, analizando los principales modelos de desarrollo identitario.

Las principales aportaciones científicas para la despatologización de la homosexualidad/lesbianismo.

El concepto de homofobia/lesbofobia, los tipos de homofobia/lesbofobia existentes y la clasificación en función del contexto en el que tiene lugar.

Se realiza un análisis de la identidad lésbica, a través del cuerpo, de la experiencia, de las identidades naturales y las sexualidades normativas frente a las alternativas periféricas, para llegar a la visión de identidad lesbiana como movimiento de acción, se hace un breve recorrido por los movimientos lesbianos organizados del Estado español, para terminar analizando el papel de la identidad lesbiana como eje de resistencia y organización política.

Se realizó una revisión de la dicotomía fem y butch, para posteriormente analizar la rebelión de lo lesbiano frente a la heteronorma, a través de las ficciones, el lenguaje y la deconstrucción de la heteronormatividad desde su epicentro (falocentro).

Una revisión de los discursos mediáticos sobre el amor, la atracción y sus modelos, además de analizar los espacios "on line", la identidad digital, las redes sociales, las app, las nuevas tecnologías, y la incidencia que pueden tener en la propia identidad.

Se plasma el análisis de las series, webseries y películas visionadas, para trazar un perfil del personaje lesbiano predominante.

También se analizan a través de la información aportada por las participantes cuestiones como la tipología de lesbianas, lesbofobia, referentes y visibilidad lésbica, espacios de ocio e internet.

Se realiza la verificación de las hipótesis. Utilizando la información de las 
participantes y el análisis de las hipótesis, para realizar una breve conexión entre el marco teórico y la investigación empírica.

Finalmente se enuncian las conclusiones y se plasman unas líneas de investigación futuras, que ya se están trabajando.

En último lugar aparece la bibliografía de referencia, usada en la tesis, recogida a lo largo de varios años de interés investigador por el tema.

\section{BIBLIOGRAFÍA CITADA}

APARICI, R. (coord.) (1996). La revolución de los medios audiovisuales. Educación y nuevas tecnologías. Madrid: Ediciones La Torre.

ARRIAZU MUÑOZ, R. (2007). “¿Nuevos medios o nuevas formas de indagación?: Una propuesta metodológica para la investigación social on-line a través del foro de discusión". "FQS" Forum: Qualitative Social Research/Sozialforschung, vol. 8, $\mathrm{n}^{\circ} 3$.

BERGER, P.L. \& LUCKMANN, T. (1978). La construcción social de la realidad. Madrid: Amorrortu-Murguia.

CHATMAN, S. (1990). Historia y discurso. La estructura narrativa en la novela y en el cine. Madrid: Taurus.

DANCEY, C. P. (1990). "Sexual orientation in women: an investigation of hormonal and personality variables". Biol Psychol, 30 (3), pp. 251-264.

DE LAURETIS, T. (1993). "Sujetos excéntricos: La teoría feminista y la conciencia histórica". En Cangiano, M. y Du Bois, L. (eds.). De mujer a género: teoría interpretación y practica feminista en las ciencias sociales. Buenos Aires: Centro Editor de América Latina.

ESTEBAN, MáL. (2004). Antropología del cuerpo. Género, itinerarios corporales, identidad y cambio. Barcelona: Edicions Bellaterra.

FISKE, J. (1997). Television culture. London: Routledge.

FOUCAULT, M. (1978). Historia de la Sexualidad: 1, 2 y 3. La voluntad del saber. Madrid: Siglo XXI Editores.

FRANCISCO, A. y MOLINER, L. (2011). "Porque la visibilidad importa. Una propuesta para trabajar la diversidad sexual en la ESO a través de la educación en medios". Revista de Educación Inclusiva, 2, pp. 147-168. 
FORÉS, A. y GRANÉ, J. (2008). La resiliencia. Crecer desde la adversidad. Barcelona: Plataforma Editorial.

FUSS, D. (1999). "Dentro/Fuera". En Carbonell, N. y Torras, M. (eds.). Feminismos literarios. Madrid: Arco Libros.

GAUNTLETT, D. (2002). Media, Gender and Identity: An Introduction. New York, NY: Routledge.

GIDDENS, A. (1992). La transformación de la intimidad. Sexualidad, amor y erotismo en las sociedades modernas. Madrid: Cátedra.

GONZÁLEZ, C. (2011). "Visibilidad y diversidad lésbica en el cine español. Cuatro películas de la última década". Icono 14. Revista de Comunicación y Nuevas Tecnologías, 9, pp. 221-255.

HINE, C. (2004) Etnografia virtual. Barcelona: Editorial UOC. Colección Nuevas Tecnologías y Sociedad.

MIRA, A. (2004). De Sodoma a Chueca: historia cultural de la homosexualidad en España 1914-1990. Madrid: Egales.

OSBORNE VERDUGO, R. (2012). Mujeres bajo sospecha. Memoria y sexualidad 1930-1980. Madrid: Fundamentos.

PLATERO, R.(L.) (2008). "Las lesbianas en los medios de comunicación: madres, folclóricas y masculinas". En Platero, R. (L.) (coord.). Lesbianas. Discursos y representaciones. Madrid: Melusina, pp. 307-338.

PLATERO, R.(L.) (2009). “La construcción del sujeto lésbico”. LES Online, 1 (1), pp. 36-44.

SALA, A. y DE LA MATA BENÍTEZ, M. (2008). "La construcción dialógica de la identidad lésbica”. En García Jiménez, A., Núñez Puente, S. y Pérez-Amat, R. (coords.). Comunicación, identidad y género. Madrid: Fragua. Vol. 1, pp. 181191.

SANFELIÚ, L. (1996). Juego de Damas. Aproximación Histórica al Homoerotismo Femenino. Málaga: Ed. Atenea.

SUÁREZ BRIONES, B. (2013). Las lesbianas (no) somos mujeres. En torno a Monique Witting. Vigo: Suárez Briones

SUÁREZ BRIONES, B. (2014). Feminismos lesbianos y queer: Representación, visibilidad y políticas. Madrid: Plaza y Valdés. 
TURKLE, S. (1997). La vida en la pantalla: la construcción de la identidad en la era de internet. Barcelona: Paidós.

TRUJILLO, G. (2009). "Del sujeto político la Mujer a la agencia de las (otras) mujeres: el impacto de la crítica queer en el feminismo del Estado español". Política y Sociedad, 46 (1), pp. 161-172.

WITTING, M. (1980). Pensamiento heterosexual y otros ensayos. Barcelona: Egales. 